\title{
Single Filament Mechanical Characterisation of Hemp Fibres for Reinforcing of Composite Materials
}

\author{
C. Romão*, P. Vieira**, F. Peito***, A.T. Marques****, J.L. Esteves**** \\ * IPV - Institute Polytechnic of Viseu, Viseu, Portugal \\ ** INEGI - Institute of Mechanical Engineering and Industrial Management, Leça do Balio, Portugal \\ *** IPB - Institute Polytechnic of Bragança, Bragança, Portugal \\ **** FEUP - Faculty of Engineering of University of Porto, Porto, Portugal
}

\begin{abstract}
The work described in this paper refers to the mechanical characterisation of Portuguese natural hemp fibres, for the utilisation on the production of composite materials with an epoxy matrix.

A single filament mechanical characterisation is made, for fibres with and without a cleaning bath from a solution of sodium hydroxide, with the propose of increasing the adherence fibre/matrix.
\end{abstract}

\section{Introduction}

Today the search for new, recyclable and renewable materials is leading the researchers in new ways. Natural products are emerging and some research is starting in this matter. In our work we are going to characterise mechanically the Portuguese natural hemp fibre. The single filament characterisation is made according to the norm ASTM D 3822. The tests were made with the fibre in is natural state and with a surface treatment called mercerization. The steps of all the work are described in this paper. Starting with the sample preparation, the surface treatment, the measuring of the fibres before and after the tests and finally the results discussion.

\section{Fibre preparation}

The fibre is placed, aligned with the longitudinal axis of the cardboard frame as shown in figure 1. This disposition gives us the possibility of assembling the sample in the testing machine. The connection between the cardboard frame and the hemp fibre was made with cianoacrylate glue.

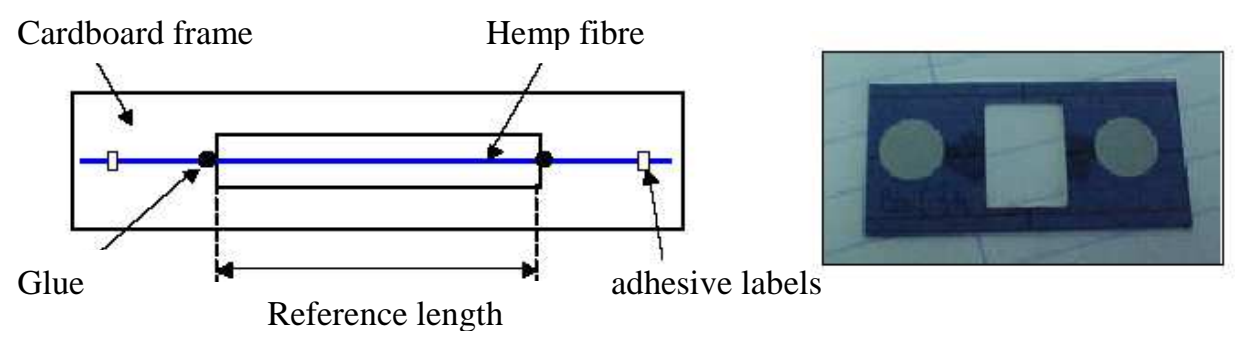

Figure 1: Assembling of the hemp fibre in the cardboard frame

Due to the small length of the monofilament hemp fibre, each fibre was positioned previously with adhesive labels. The distance between the two glue drops define the 
distance between the grips, that is to say, the length of reference of the traction test. The selection of this length is of extreme importance, because normally the traction resistance decreases, as the length of the fibre increases, as well as the error associated to the results of the traction tests.

\section{Measuring the fibres}

After assembling the hemp fibres in cardboard frames, it was necessary to measure the traverse section for determination of the respective area, measure that is necessary for the calculation of the rupture tension and the traction elasticity modulus.

The variability of dimensions and of geometry of the hemp fibres also happens along each fibre. This fact eliminated the hypothesis of being considered a medium area and forced to us to make individual measures.

These measuring were made along the length of each fibre, more concretely each 2.5 $\mathrm{mm}$. So, for the samples with reference lengths of $5 \mathrm{~mm}$ were made three measures (extremities and centre) while for the samples with reference lengths of $10 \mathrm{~mm}$ were made five measures (extremities, centre and between the centre and the extremities of the fibres).

In spite of the hemp fibres generally possess transverse sections of polygonal geometry, it was considered, for this work, a circular geometry.

The diameter measuring was made using two different techniques: the technique of light diffraction and the optical microscopy. The first was in the beginning very attractive, due to the high number of samples to be measure. However, after the tests and face to the results obtained, were considered the possibility of this method introduced significant errors in the calculated values of the mechanical properties of the fibres. The origin of these possible errors could reside in the fact that the measures could have been made in places with defects or with superficial sludge's. Because of that, we repeated the whole process using the optical microscopy.

\section{LIGHT DIFRACTION TECHNIQUE}

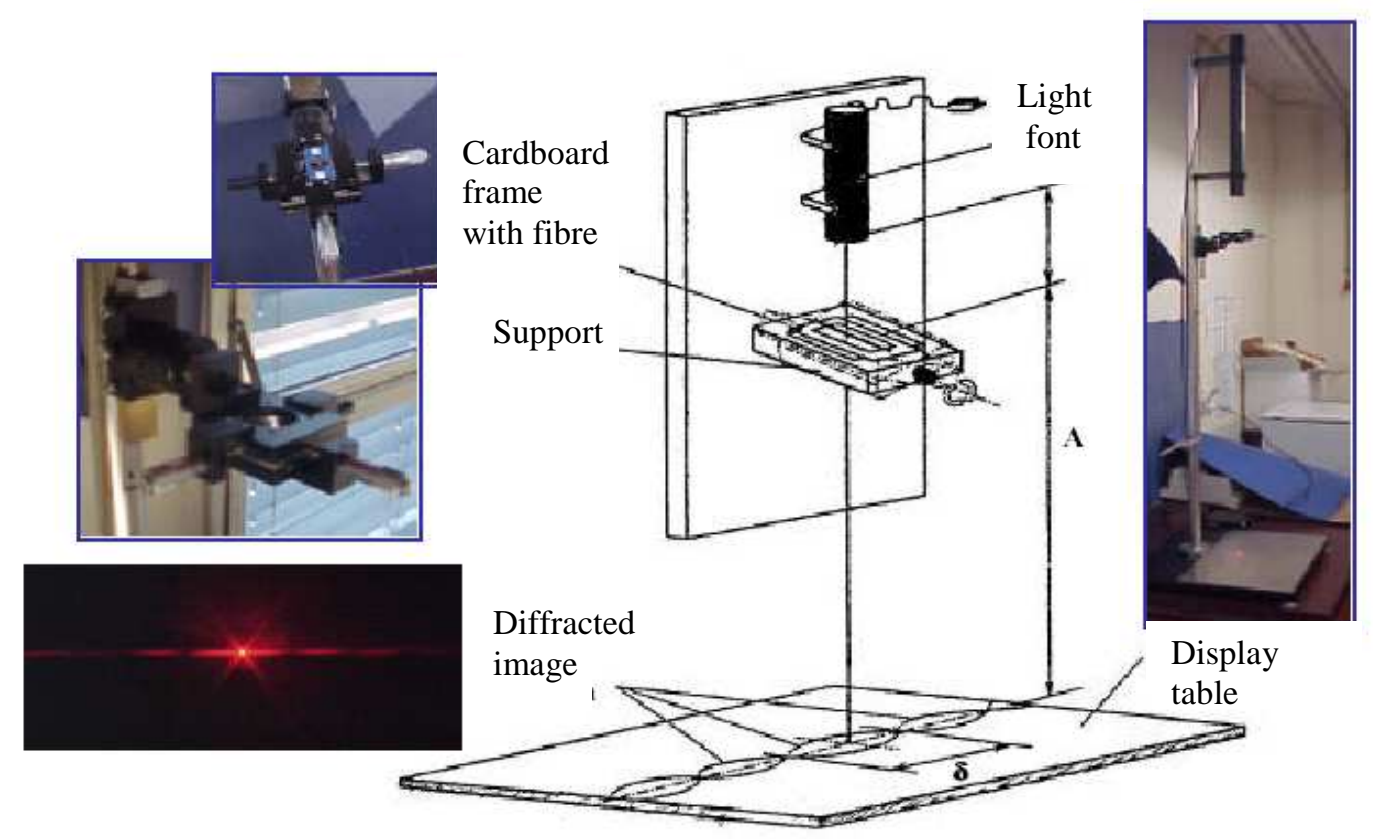

Figure 2: Light diffraction equipment 
As we can see in figure 2 the cardboard frame with the fibre is placed in the support. After this we project the diffracted light that changes the angle we passing trough the fibre. After measuring the distance between the two first nodes of the image projected in the display table, we could using equation (1) arrive to the diameter.

$$
\begin{aligned}
& \text { If } A>>\frac{\pi * d_{f}^{2}}{4 * \lambda_{H e-N e}} \text { then } \quad d_{f}=\frac{2 * \lambda_{\mathrm{He}-\mathrm{Ne}} * A}{\delta} \\
& \mathrm{d}_{\mathrm{f}}-\text { fibre diameter in each measure point } \\
& \lambda_{\mathrm{He}-\mathrm{Ne}}-\text { wave length of the laser beam }(0.6328 \mu \mathrm{m}) \\
& \text { A - Distance between the support and the display table }(98.1 \mathrm{~cm}) \\
& \delta \text { - Distance between the two first nodes projected }(\mathrm{cm})
\end{aligned}
$$

This measuring system is quite effective when applied to synthetic fibres however, when natural fibres are used, the image diffracted in the display table can hinder the location of the interference nodes. The smallest precision in the image diffracted can be the result, as it was already referred, of the presence of defects, of superficial sludge's in the fibres or of the geometry of the same ones.

\section{OPTIC MICROSCOPY}

The second diameter measures were made using an optic microscopic equipment. Using this equipment we could confirm (or not) the first measures made and see the rupture crack. We could also observe some defects in the fibres. In figure 4 some of these images can be seen.
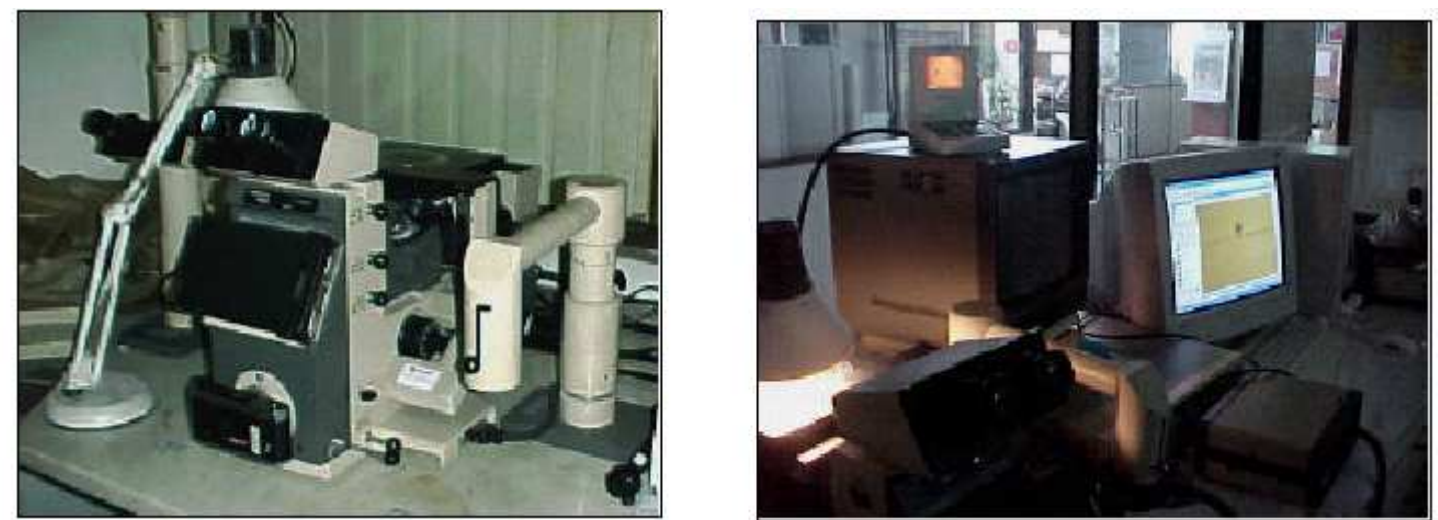

Figure 3: The microscopic equipment
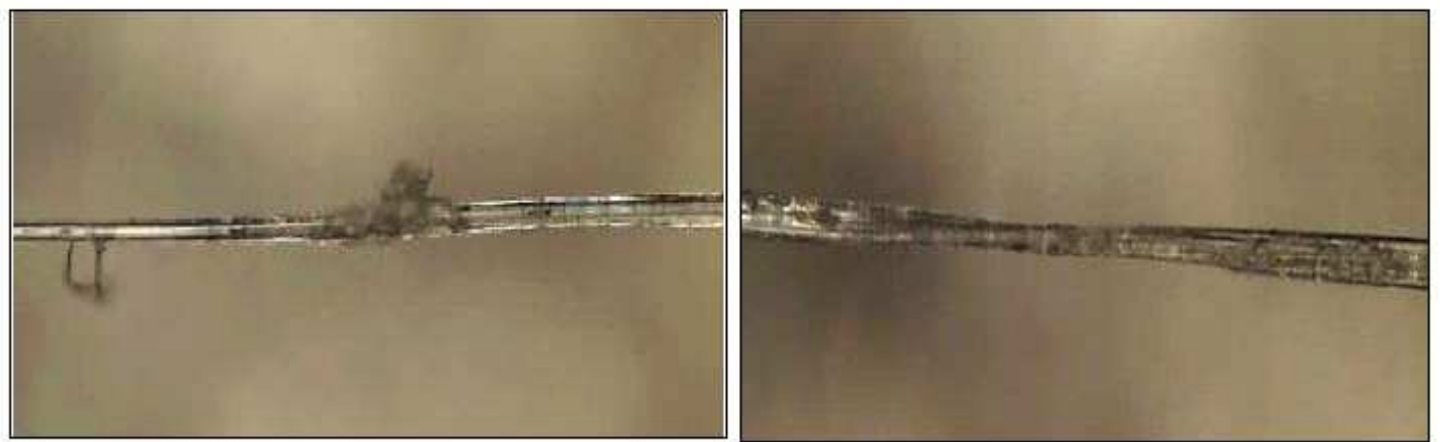

Figure 4: Some defects in the fibres 
The results of these measures are shown in table 1:

\begin{tabular}{|c|c|c|c|c|c|c|c|}
\hline & & \multicolumn{6}{|c|}{ Fibre diameter $(\mu \mathrm{m})$} \\
\hline & & \multicolumn{3}{|c|}{ Without treatment } & \multicolumn{3}{|c|}{ Treatment of mercerization } \\
\hline & & $\mathrm{L}_{0}=5 \mathrm{~mm}$ & $\mathrm{~L}_{0}=10 \mathrm{~mm}$ & Total & $\mathrm{L}_{0}=5 \mathrm{~mm}$ & $\mathrm{~L}_{0}=10 \mathrm{~mm}$ & Total \\
\hline \multirow{5}{*}{$\begin{array}{l}\text { Light } \\
\text { diffraction } \\
\text { technique }\end{array}$} & Average & 23.5 & 22.0 & 22.4 & 21.2 & 22.1 & 21.8 \\
\hline & Stdev. & 6.0 & 5.3 & 5.6 & 5.4 & 4.7 & 5.0 \\
\hline & Minimum & 13.2 & 11.2 & 11.2 & 13.4 & 12.2 & 12.2 \\
\hline & Maximum & 36.5 & 37.6 & 37.6 & 40.7 & 34.5 & 40.7 \\
\hline & $\mathrm{N}^{\circ}$ fibres & 27 & 40 & 67 & 31 & 41 & 72 \\
\hline \multirow{5}{*}{$\begin{array}{l}\text { Optic } \\
\text { microscopy }\end{array}$} & Average & 26.1 & 23.5 & 24.3 & 22.4 & 24.5 & 23.8 \\
\hline & Stdev. & 6.7 & 5.4 & 5.9 & 4.7 & 5.3 & 5.2 \\
\hline & Minimum & 14.2 & 12.9 & 12.9 & 12.0 & 12.3 & 12.0 \\
\hline & Maximum & 42.0 & 38.8 & 42.0 & 43.7 & 41.8 & 43.7 \\
\hline & $\mathrm{N}^{\circ}$ fibres & 27 & 40 & 67 & 31 & 41 & 72 \\
\hline
\end{tabular}

Table 1: Values of the fibre measuring

We can see in this table that the Stdev (Standard deviation) is very high, more or less $23.5 \%$ of the average value. This is due to the variability in dimensions of the natural hemp fibres.

We can see that the mercerization treatment did decrease the diameter. It would be expected that, due to the removal of substances, the medium diameter of the fibres decreased, which was not always verified. This fact should result of the great variability in dimensions that characterize the vegetable fibres.

\section{Surface treatment}

With the hemp fibres a surface treatment has been done to increase the fibre/matrix adhesion. This treatment (mercerizing) is made in some steps. First step is to perform an immersion bath. Two hours in a solution of $8 \%$ in volume of Sodium Hydroxide $(\mathrm{NaOH})$ with distilled water. During this process the bath was stirred continuously using a mechanical agitator (figure 5). At the end the solution presented a yellow colour because of the substances removed from the fibre. The next step is cleaning the fibres several times in a distilled water bath, until the water is clean. After several baths, a neutralizing solution of $25 \%$ in volume of acetic acid is used. Again, more two or three baths with distilled water and the treatment is finished. To dry the fibres we left them 5 days at ambient temperature, and then six hours at $60^{\circ} \mathrm{C}$ in an oven (figure 6). [3-5]

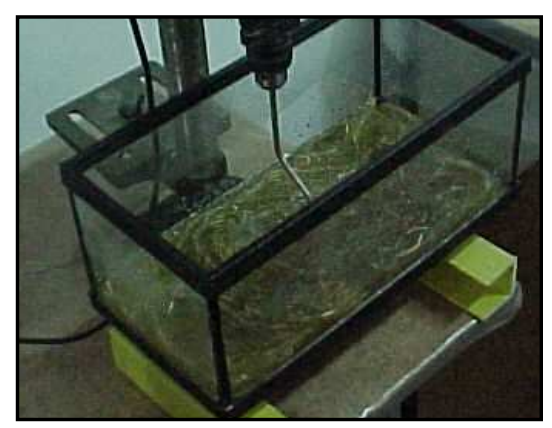

Figure 5: Sodium Hydroxide bath

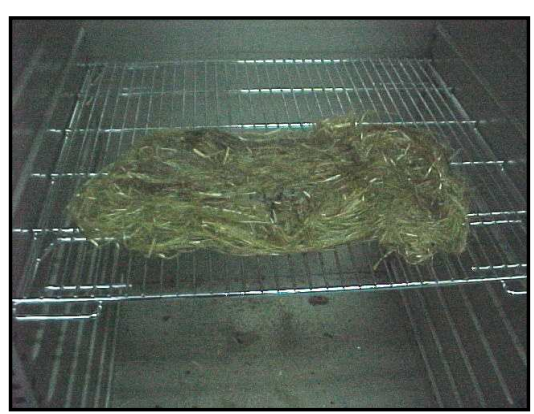

Figure 6: Fibres in the oven 


\section{Mechanical tests}

The testing machine was equipped with a load cell of 2,5 $\mathrm{N}$ and with pneumatic claws adapted for the fixation of the cardboard frames. The superior claw was freely suspended in the load cell, so that when a traction force was applied, the claw auto aligns itself with the longitudinal axis of the fibre. Before beginning each test, the lateral parts of the cardboard frame were cut through an incandescent metallic wire, so that only the hemp fibre is submitted to the traction force. Figure 7 show the all process.
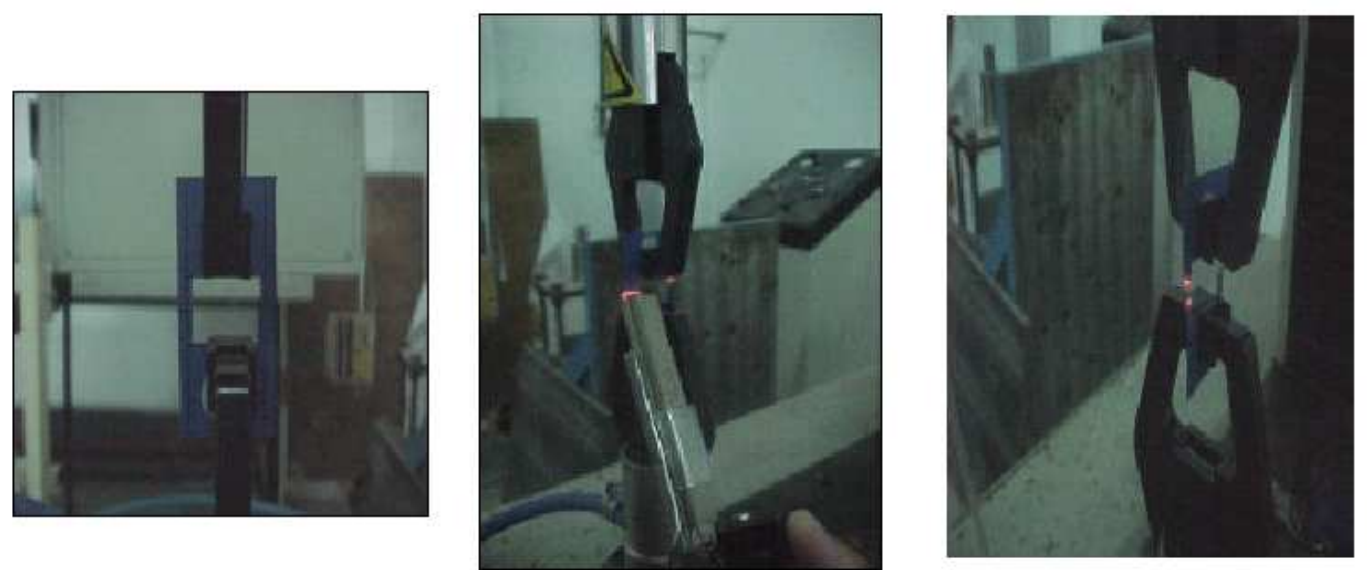

Figure 7: Fixation in the pneumatic claws / Cutting the cardboard frame / Ready for testing

In agreement with the norm ASTMD 3822 [23], the test speeds, were of $0.5 \mathrm{~mm} / \mathrm{min}$ and $1,0 \mathrm{~mm} / \mathrm{min}$, respectively, for the samples with lengths of reference of $5 \mathrm{~mm}$ and of $10 \mathrm{~mm}$. The tests were preformed in an atmosphere under temperature conditions and relative humidity of $21 \pm 1{ }^{\circ} \mathrm{C}$ and $65 \pm 2 \%$, respectively.

Analyzing through optical microscopy the rupture section of the tested fibres, we could verify that the rupture happened by forming a plane surface separation [Figure 8 ] or by an irregular laceration of the structure [Figure 9].
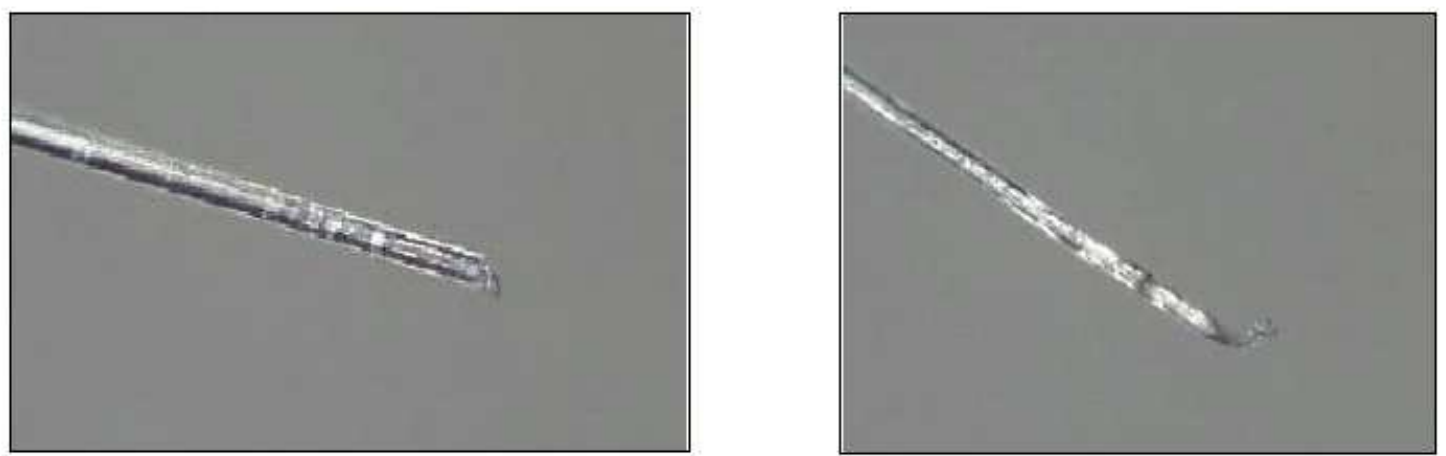

Figure 8: Plane surface separation

Figure 9: Irregular laceration of the structure

In table 2 we present the rupture diameters, used in the calculation of the rupture tension of the hemp fibres. We used these new values, because the average value 
calculated measuring the fibre in several points could have an error. Using the rupture value for tests we eliminate that error.

\begin{tabular}{|c|c|c|c|c|c|c|c|}
\hline & & \multicolumn{6}{|c|}{ Fibre diameter $(\mu \mathrm{m})$} \\
\hline & & \multicolumn{3}{|c|}{ Without treatment } & \multicolumn{3}{|c|}{ Treatment of mercerization } \\
\hline & & $\mathrm{L}_{0}=5 \mathrm{~mm}$ & $\mathrm{~L}_{0}=10 \mathrm{~mm}$ & Total & $\mathrm{L}_{0}=5 \mathrm{~mm}$ & $\mathrm{~L}_{0}=10 \mathrm{~mm}$ & Total \\
\hline \multirow{5}{*}{$\begin{array}{l}\text { Light } \\
\text { diffraction } \\
\text { technique }\end{array}$} & Average & 23.4 & 21.0 & 21.9 & 20.4 & 21.2 & 20.8 \\
\hline & Stdev. & 5.8 & 4.1 & 5.0 & 5.3 & 4.9 & 5.1 \\
\hline & Minimum & 13.2 & 13.5 & 13.2 & 14.5 & 14.1 & 14.1 \\
\hline & Maximum & 35.5 & 31.8 & 35.5 & 33.6 & 31.0 & 33.6 \\
\hline & $\mathrm{N}^{\circ}$ fibres & 27 & 40 & 67 & 31 & 41 & 72 \\
\hline \multirow{5}{*}{$\begin{array}{l}\text { Optic } \\
\text { microscopy }\end{array}$} & Average & 24.6 & 20.9 & 22.4 & 21.9 & 22.2 & 22.0 \\
\hline & Stdev. & 5.5 & 4.8 & 5.4 & 3.5 & 4.5 & 4.1 \\
\hline & Minimum & 14.2 & 10.4 & 10.4 & 15.4 & 14.4 & 14.4 \\
\hline & Maximum & 34.7 & 29.6 & 34.7 & 29.8 & 35.8 & 35.8 \\
\hline & $\mathrm{N}^{\circ}$ fibres & 27 & 40 & 67 & 31 & 41 & 72 \\
\hline
\end{tabular}

Table 2: Values of the rupture section

The average rupture diameter is of the same order of greatness that the medium diameter of the fibres, presented in the table 1.

Although the medium values obtained by the two measuring techniques are identical it was verified great differences between some fibres rupture diameter and the medium diameter of the respective fibre, originating this situation incorrect values in the tensile strength.

\section{Results}

When represented graphically, the force/displacement values measured during the test present a typical aspect shown in figure 10 fibres without treatment and in figure 11 for fibre with mercerization treatment.
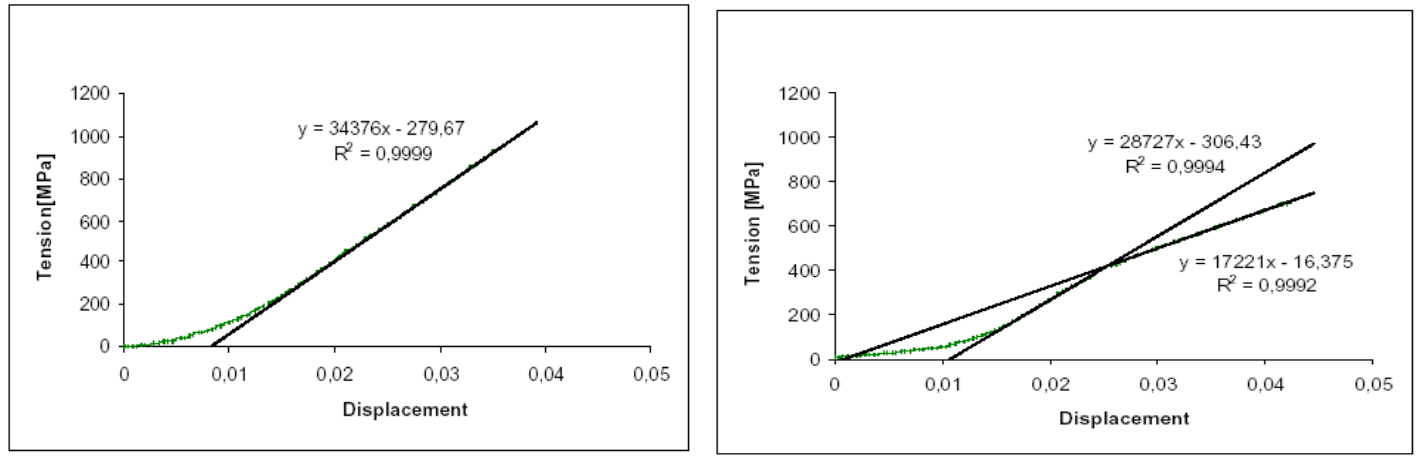

Figure 10: T/D Without treatment

Figure 11: T/D With mercerization treatment

In the beginning of the tests and in both curves we verified that, the force supported by the fibres varies in a non lineal way with the displacement. This initial behaviour is due to the fact that the fibres are not perfectly aligned, being necessary to make a correction in the displacement of the mobile dash so that we can determine the effective displacement, during the test. To accomplish this correction it was necessary to extrapolate the linear portion of the experimental curve to intersect the abscissas axis. 
Starting from the analysis of the previous figures, it was possible to verify that the curve strength-displacement corresponding to the treated fibres has two linear portions. For these fibres two modules of elasticity were determined corresponding, one to the first linear portion, and the other to the second linear portion.

After the tests made we used the following formulas to calculate the tension strength (2) and the Young Modulus (3).

$$
\sigma_{r}=\frac{F_{r}}{A_{r}}
$$

$\sigma_{\mathrm{r}}-$ fibre tension strength

$\mathrm{F}_{\mathrm{r}}$ - Traction force at rupture

$\mathrm{A}_{\mathrm{r}}-$ Rupture section of the fibre

$$
E=\frac{\Delta \sigma}{\Delta \varepsilon}=\frac{F^{*} L_{0}}{A^{*} \Delta L}
$$

E - Young Modulus

$\Delta \sigma-$ Tension strength variation

$\Delta \varepsilon$ - Displacement variation

$\mathrm{F}$ - Traction force

$\mathrm{L}_{0}-$ Reference length

A - Average of the transversal section of the fibre

$\Delta \mathrm{L}-$ Displacement variation *

* The displacement values were corrected taking into consideration the system compliance.

The following tables show us the tension strength and the Young modulus for the fibres tested.

\begin{tabular}{|l|c|c|c|c|c|}
\hline \multicolumn{2}{|c|}{} & \multicolumn{5}{|c|}{$\begin{array}{c}\text { Tension strength } \\
{[\mathrm{MPa}]}\end{array}$} \\
\cline { 2 - 6 } \multicolumn{2}{|c|}{} & \multicolumn{2}{|c|}{$\begin{array}{c}\text { Without treatment } \\
\text { Average }\end{array}$} & \multicolumn{2}{|c|}{$\begin{array}{c}\text { Treatment of mercerization } \\
\text { Average }\end{array}$} \\
\hline \multirow{2}{*}{$\begin{array}{l}\text { Light } \\
\text { diffraction } \\
\text { technique }\end{array}$} & $\mathrm{L}_{0}=5 \mathrm{~mm}$ & 948 & 403 & 868 & 290 \\
\cline { 2 - 6 } & $\mathrm{L}_{0}=10 \mathrm{~mm}$ & 943 & 498 & 718 & 240 \\
\hline \multirow{2}{*}{$\begin{array}{l}\text { Optic } \\
\text { microscopy }\end{array}$} & $\mathrm{L}_{0}=5 \mathrm{~mm}$ & 1110 & 409 & 722 & 226 \\
\cline { 2 - 6 } & $\mathrm{L}_{0}=10 \mathrm{~mm}$ & 970 & 502 & 638 & 206 \\
\hline
\end{tabular}

Table 3: Tension strength 


\begin{tabular}{|c|c|c|c|c|c|c|c|}
\hline & \multicolumn{6}{|c|}{$\begin{array}{c}\text { Young modulus } \\
{[\mathrm{GPa}]}\end{array}$} \\
\hline & & \multicolumn{2}{|c|}{ Without treatment } & \multicolumn{4}{|c|}{ Treatment of mercerization } \\
\hline & & Aver: & STDV & & $e^{* *}$ & & \\
\hline \multirow{2}{*}{$\begin{array}{l}\text { Light } \\
\text { diffraction } \\
\text { technique }\end{array}$} & $\mathrm{L}_{0}=5 \mathrm{~mm}$ & 66 & 20 & 35 & 16 & 12 & 5 \\
\hline & $\mathrm{L}_{0}=10 \mathrm{~mm}$ & 57 & 13 & 33 & 16 & 12 & 5 \\
\hline \multirow{2}{*}{$\begin{array}{l}\text { Optic } \\
\text { microscopy }\end{array}$} & $\mathrm{L}_{0}=5 \mathrm{~mm}$ & 55 & 18 & 26 & 14 & 9 & 4 \\
\hline & $\mathrm{L}_{0}=10 \mathrm{~mm}$ & 50 & 13 & 24 & 13 & 8 & 4 \\
\hline
\end{tabular}

Table 4: Young modulus

** The two modulus shown in this table are of the two lines explained above. Only the first line was taken in consideration for the rest of the appreciation.

In both cases we tested 27 fibres without treatment and 31 with the mercerization treatment. The standard deviation is very high. The number of tests should increase to solve this problem. The fibre variability is definitely influencing these results, and so the number of tests that we need to do in natural fibres should increase drastically. We can see that with the increase of the reference length, the properties worsened, and that is logic. What we didn't expect is that the mercerization treatment worsened the tension strength in $25 \%$ and the Young modulus in $48 \%$. Further study should be made to better understand this. Other significant analysis is the fact that the optic microscopy worsened the results in about $10 \%$. This is due to the improvement in calculating the fibre section.

\section{Conclusions}

In this study, in which we characterize the natural hemp fibres and compare them with mercerized treated ones, we arrived to several conclusions. Natural fibres are in reality difficult to characterize. The results obtained are far from good, the standard deviation in some cases is superior to $50 \%$. This is too much. The section of the fibre is very difficult to calculate, because there is no geometric pattern associated to it. We calculate the section as if there fibre was cylindrical. The results using optic microscopy is more accurate, but the cylindrical simplification is probably still giving some errors to the process.

It is necessary to point the research in the cleaning and in the surface treatment of the fibre. Only with good surface treatment we can obtain good mechanical properties. To evaluate the influence of the alteration of the chemical composition and of the morphology of the cellular wall in the properties of the fibres in study, took place a treatment of mercerization to a group of hemp fibres

That treatment proved to be inappropriate, because it didn't improve the mechanical properties, but instead it worsened those properties. The acid probably damaged the cellular wall, and that was the reason for this problem. Future works should be made 
find a treatment that doesn't change the mechanical properties of the fibres and increases the adhesion fibre /matrix.

\section{References}

[1] C. Romão, "Study of the Mechanical Behaviour of Composite Polymeric Materials Reinforced with Natural Fibres", Dissertation presented for obtaining a Master's degree in Mechanical Engineering, from the Engineering Faculty in the University of Porto, April, 2003.

[2] Project SAPIENS POCTI/40201/EME/2001, "Mechanical behaviour of Composites of Polymeric Matrix Reinforced with Natural Fibres", Report of Annual Progress, $1^{\circ}$ year of activity, 2002.

[3] Peters R.H. "Textile Chemistry I: The Chemistry of Fibres", Elsevier Publishing Company, 1963.

[4] Peters R.H. "Textile Chemistry II: Impurities in Fibres, Purification of Fibres", Elsevier Publishing Company, 1967.

[5] Rowell R.M. "Chemical Modification of Agricultural Fibres for Property enhanced Composites", Cap. V, Project: Modification of Lignocellulosics for Advanced Materials and New Uses, http://www.fppl.fs.fed.us, 1995.

[6] P. Vieira, C. Romão, A.T. Marques, J.L. Esteves, Mechanical Characterisation of Natural Fibre Reinforced Plastics, MATERIAIS 2003, II International Materials Symposium April, 14-16. 